\title{
Emotional Intelligence and Academic Achievements of Elementary Pupils in Mathematics of Batangas State University ARASOF Nasugbu, Batangas: Input to a Proposed Development Plan
}

\section{Lorna V. Dacillo}

Faculty, College of Teacher Education Lab.School Elem., Batangas State University ARASOFNasugbu

\section{Abstract}

The study sought to find the correlation between the emotional intelligence and academic performance in mathematics of the elementary pupils of Batangas State Unversity ARASOF Nasugbu. A standardized questionnaire entitled Bar-On Emotional

Corresponding Author: Lorna V. Dacillo

lornadacillo@yahoo.com.ph

Received: 23 April 2018

Accepted: 8 May 2018

Published: 4 June 2018

Publishing services provided by Knowledge E

(c) Lorna V. Dacillo. This article is distributed under the terms of the Creative Commons

Attribution License, which permits unrestricted use and redistribution provided that the original author and source are credited.

Selection and Peer-review under the responsibility of the IRCHE 2017 Conference Committee.
Quotient Inventory: Youth Version was used to measure the emotional intelligence of the seventy-five (75) pupils which includes intrapersonal, interpersonal, stress management, adaptability, general mood, positive impression scale and total emotional quotient of the respondents. The final grade in mathematics was used to measure the academic performance in mathematics. The intrapersonal skill of the pupils show that they demonstrate their feelings honestly and for the interpersonal skills having friends is the most important thing for them. The study also shows that respondents have adequate emotional and social capacity including coping for daily demands and pressures.The findings of the study showed that the emotional quotient had no significant difference in terms of their gender and ages and that there is no relationship between emotional and academic performance in mathematics of the elementary pupils of Batangas State University - ARASOF Laboratory School. Emotional intelligence is seen as an important element in life based from different studies that is why additional activities about emotional quotient and mathematics was recommended so students will excel in mathematics and be people-smart.

Keywords: academic performance, emotional intelligence, mathematics

\section{Introduction}

Emotional intelligence has become a popular topic of interest in the academic commuG OPEN ACCESS 
to monitor one's own and others' feelings and emotions, to discriminate among them, and to use this information to guide one's thinking and action as cited in a research conducted by Bryant (2007) [1].

The ability to assess and affect situations and relationships with other people also plays a role in emotional intelligence. This measurement is intended to be a tool that is similar to intelligence quotient (IQ), which is a measurement of a person's intellect. There is much debate surrounding the legitimacy of Emotional Quotient (EQ), however, primarily because there is no standard of measurement.

In the research of Bryant (2007) [1] about emotional intelligence she stated that the concept of "Emotional Intelligence" has been of interest for years. In the field of psychology the roots of emotional intelligence can be traced back to the beginnings of intelligence testing movement when, Thorndike (1920, [2]) was the first to identified the aspect emotional intelligence as social. According to him, the concept of social intelligence refers to the ability to understand and manage men, women, boys and girls and to act wisely in humans relations. Gardner (2011, [3]) revitalized the concept of emotional intelligence with his model of multiple intelligence. Bar-On used the term EQ in his doctoral dissertation long before it gained popularity as a name to emotional intelligence and long before Salovey and Mayer (2008, [4]) published their first model on intelligence.

Mathematics is one subject that pervades life at any age and in any circumstance. Thus, its value goes beyond the classroom and the school. Mathematics as a school subject, therefore, must be learned comprehensively and with much depth. (K to 12 Basic Education Curriculum, 2013)

The desire of any educational system is to produce students who are sufficiently trained to contribute meaningfully to the development of the system and the society in general. Among all academic subjects studied at school, mathematics has distinctly contributed more to the objectives of general education of man than any other subject. Despite the importance of mathematics to the nation, a review of the performance in both internal and external examinations has revealed disturbing picture. This is giving grave concern to educators, parents, students, school administrators and the general public (Festus, 2012 [5])

It is generally agreed that mathematics must be taught during basic education, but this does not mean that mathematics education itself is not a subject of debate. Both national and international evaluations show that, on completion of basic education, many pupils' mathematics knowledge and competencies fall short of the expected level.(Artigue, 2012) 
The Philippines lags behind the rest of the world in mathematics and science expertise, as shown by Filipino students' dismal scores in global tests like the 2004 Trends in International Math and Sciences Study.(Lee-Chua, 2009 [6]).This shows that the performance of students in our country was not performing well when it comes to mathematics

The deteriorating performance of Filipino students in the national and international mathematics tests for the last decade has become a major challenge to Philippine education. Mathematics education in the Philippines is one of the priority concerns of the Department of Education (DepEd). Students' NAT for four succeeding years (20062009) in both elementary and secondary levels registered below mastery level of $75 \%$. Unfortunately, the international and national trend of Filipino students' poor performance is also reflected in both regional and local levels. Hence, the alarming performance of the Filipino students in mathematics locally, nationally and internationally necessitates urgent decisions and actions from all education sectors. Looking particularly into the NAT results, DepEd singled out low reading competence as a primary factor for the failure of public school students in mathematics. Along this line, appropriate measures were undertaken to improve students' performance in English and mathematics. Despite all these government efforts to improve the quality of mathematics performance as well as reading skills, the problem on these two areas still persist.(Imam,Abas, Maripaz, 2012 [7])

In President Benigno S. Aquino III's 10-point basic education agenda published by Pagtinabangay Foundation Inc. last March 29, 2010 it was stated that he will rebuild the science and math infrastructure in schools so that we can produce more scientists, engineers, technicians, technologists and teachers in our universities so that this country can be more globally competitive in industry and manufacturing. This showed that the president was really giving importance to mathematics and last May 15, 2013 he signed the Republic Act 10533 which is also known as the "Enhanced Basic Education Act of 2013". It was stated that the Deped shall adhere to different standards which includes a curriculum that is relevant, responsive and research based and the curriculum shall use the spiral progression approach to ensure mastery of knowledge and skills after each level in different subjects including mathematics.

Through many years of teaching Mathematics in the elementary level, the researcher was able to observe the poor performance of many students in Mathematics. She already conducted remedial teaching, tutorial, used of different technologies like LCD projector in teaching and different strategies but still some pupils cannot understand and master the concepts in Math. 
Emotional intelligence can be linked to children's academic success - yet no study focused on the role those facets of emotional intelligence and dimensions of study orientation play in math's achievement.(Erasmus, 2013 [8]). It is considered that emotional intelligence is a factor that is useful in understanding and predicting one's performance at work and school.

Mathematics is included in the academic subjects, actually it is one of the most important subjects that we have because mathematics is used in daily life but still poor performance in math is a worldwide concern.

It is in the light of the foregoing information that the researcher has been motivated to conduct a correlational research between the Emotional Quotient and Academic Achievement of Elementary Pupils in Mathematics of Batangas State University ARASOF in Nasugbu, Batangas

\section{Objectives of the Study}

The study aimed to correlate emotional quotient and academic achievement of elementary pupils in mathematics for A.Y. 2015 - 2016 of Batangas State University ARASOF Nasugbu, Batangas.Specifically, it sought answers to the profile of the respondents in terms of age and gender, the academics performance in mathematics, the emotional intelligence based on different aspects. The study would like to know if there is a significant difference between the emotional intelligence of the respondents when group based on the profile variable and finally to find out if there is a correlation between emotional quotient and academic performance in mathematics of the elementary pupils of Batangas State University-ARASOF Laboratory School.

\section{Materials and Methods}

The researcher used the descriptive method of research to determine the needed information on the correlation of emotional intelligence and academic performance in mathematics of elementary pupils of Batangas State University, College of Teacher Education Laboratory School.

The type of descriptive research method used in this study is correlational research that described what exists at the moment (conditions, practices, processes, structures etc.) This method attempted to collect data to determine whether, and to what extent, a relationship exists between two or more quantifiable variables. The degree of relationship is expressed in terms of a coefficient correlation. If the relationship 
exist between variables, it implies that scores on one variable are associated with or vary with the scores on another variable. The exploration of relationship between variables provides insight into the nature of the variables themselves as well as an understanding of their relationships.

In a correlation research, no attempt is made to control or manipulate the variables as in experimental design; however, the correlation statistic is used to describe and measure the degree of relationship between two or more variables or sets of scores.

This study used the correlational survey research design. This was used to determine if there is any relationship between Emotional Intelligence and academic achievement of Batangas State University ARASOF Laboratory School elementary students in Mathematics. The EQ of the students was correlated with their final grade (FG) in Mathematics was taken as true measure of academic performance in Mathematics. Descriptive method using the Bar-On EQ-i:YV questionnaire was used in determining the emotional quotient of the students. The final grade of the pupils in Mathematics during the school year 2015-2016 was used to get the Mathematical performance of the pupils.

The respondents of the study were elementary pupils of Batangas State University ARASOF Nasugbu ages 7 and above who were enrolled this academic year 2015 2016. Seventy-five out of one hundred thirty-nine students enrolled in the laboratory elementary based from their age, parents' approval and emotional readiness were the respondents of the study. The student's academic performance was limited to the final grade in mathematics for school year 2015 - 2016 using the assessment in the $\mathrm{K}$ to 12 Curriculum.

Respondents of the Study

The respondents of the study were the elementary pupils from Grade II to Grade V of the Laboratory School Elementary.

The respondents were selected based on their ages because the Bar-On EQ:YV instrument was designed to measure emotional intelligence in young people aged 7 to 18 years. Since the instrument was a self-report measure, it is not recommended for persons who are unwilling or unable to cooperate in responding honestly to a questionnaire and pupils who are disoriented and severely impaired which also taken into consideration during the selection of the respondents. Seventy-seven students were selected based from the given criteria and letters asking for permission to participate in the study was sent to the parents and 75 pupils were allowed to be the respondents in this study. 


\section{Research Instrument}

Based on the original EQ-i for adults, the EQ-i:YV ${ }^{T M}$ measures the level of emotional and social functioning in children and adolescents. As a strength based assessment, this product highlights areas of positive functioning as well as areas for development. It can be used by psychologists, teachers, school counselors, social workers, and psychiatrists to identify an individual's strengths and weaknesses in order to help that individual develop the skills needed for academic, personal, and social success. The five dimensions of Bar-On's Youth Version can be summarized to: (a) Intrapersonal Emotional Quotient (EQ), (b) Interpersonal EQ, (c) Stress Management EQ, (d) Adaptability EQ, and (e) General Mood EQ. Intrapersonal EQ includes the abilities to understand and express one's own emotions, actualize one's potential and be self-reliant while Interpersonal EQ allows one to identify others' emotions and relate appropriately. Stress Management EQ subsumes the ability to manage and control emotions. Adaptability EQ characterizes the not only to adapt emotions appropriately in necessary situations, but also to solve personal and interpersonal problems and objectively validate them based on external reality. Finally, General Mood EQ includes the ability to be optimistic and content with oneself, others and life in general.

The final grades of the students in mathematics were the basis of the mathematical performance of the study.

\subsection{Data gathering procedure}

Specific steps were necessary before conducting the study, including (a) obtaining permission from Multi-Health Systems Inc. of the sister in law of the researcher and purchasing the instrument to be used in the study (b) permission from school principal (c) getting collaborative support from the thesis adviser(d) obtaining support from the school psychologist (e) identifying students who were willing to cooperate in responding honestly to a questionnaire since the instrument was not recommended for children who were disoriented of severely impaired (f) obtaining parental consent (g) administered the questionnaire to the respondents (h) answer sheet were immediately analysed and (i) request for the grades of the respondents from registrar's office.

For the statistical treatment for the first problem percentage was used to identify the profile of the respondents in terms of age and gender. For the second data which is the academic performance in mathematics the final grade in the subject was grouped 
according to the level of proficiency which include advanced for 90 and above average, proficient for $85-89$, approaching proficiency for $80-84$, developing for $75-79$ and beginning for 74 and below. For the emotional intelligence of the pupils they answered the questionnaire based on the following dimensions: intrapersonal scale; interpersonal scale; stress management scale; adaptability scale; positive impression scale; total and total emotional scale. To determine the score for each scale the researcher used the scoring guide of the BarOn EQ-i:YV of the technical manual. To determine the correlation between emotional intelligence and Mathematical Performance of the students $\mathrm{F}$ - test was used to determine if there is a relationship between emotional intelligence and academic performance of the respondents of the study. After the conduct of the study a proposed Development Plan was prepared by the researcher to enhance the academic achievement of pupils in Mathematics.

\section{Results and Discussion}

This study aimed to find out if there is a correlation between emotional intelligence and academic performance in mathematics of the elementary pupils in Batangas State University ARASOF- Nasugbu, Nasugbu Batangas.

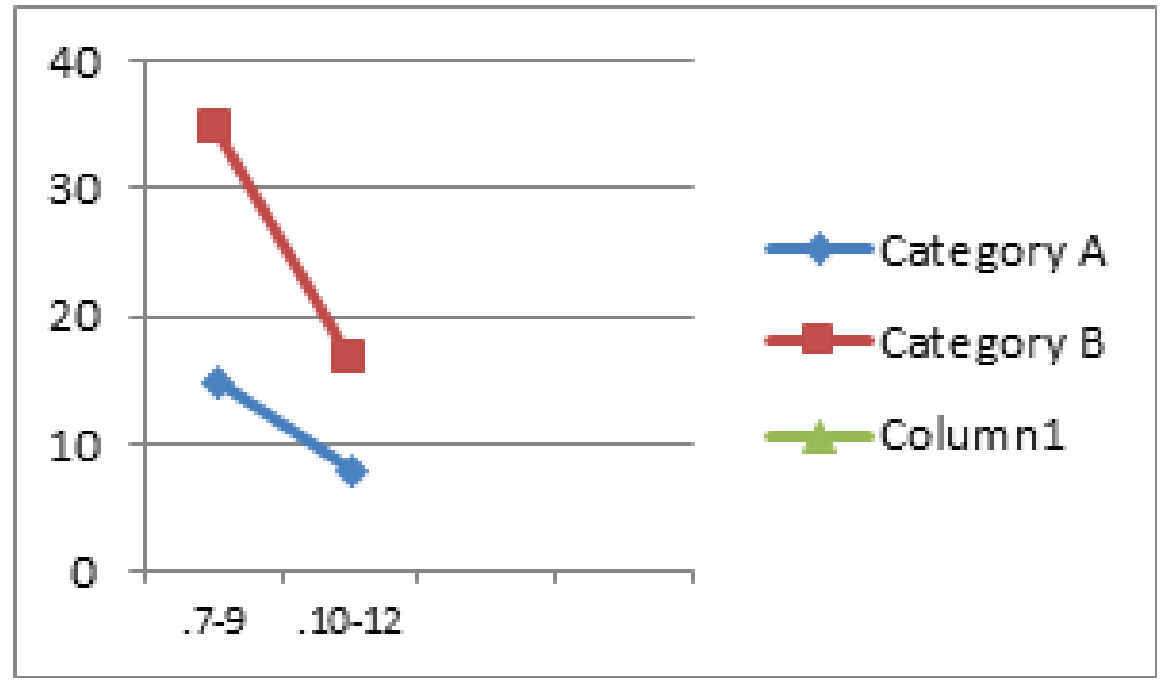

Figure 1: Profile of Pupil-Respondents in Terms of Age.

Figure 1 shows the profile of the pupil-respondents in terms of age.

As shown in the Figure, the pupil respondents are distributed to two age groups based on the BarOn EQ-I:YV instrument.Fifteen (15) or 65.22 percent of male pupils are between seven (7) to nine (9) years of age (Category A). Eight (8) or 34.78 percent male pupils are between ten (10) to twelve (12) years of age (Category B.It can be 
noted from the profile of the pupil-respondents that they are mostly female and mostly between 7 - 9 years of age.

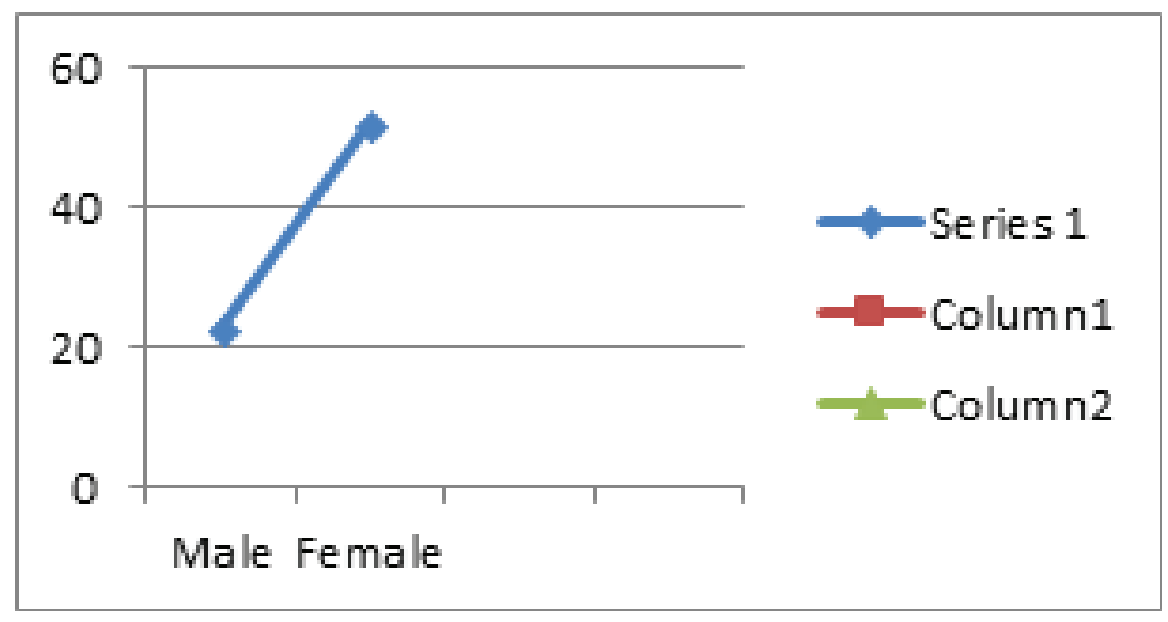

Figure 2: Profile of the Pupil-Respondents in Terms of Gender.

Figure 2 shows the distribution of the pupil-respondents in terms of gender. The male pupil-respondents are represented by twenty three (23) or $30.67 \%$ and the female pupil respondents are represented by fifty two (52) or $69.33 \%$ of the total respondents. It can be noted from the profile of the pupil-respondents that they are mostly female.

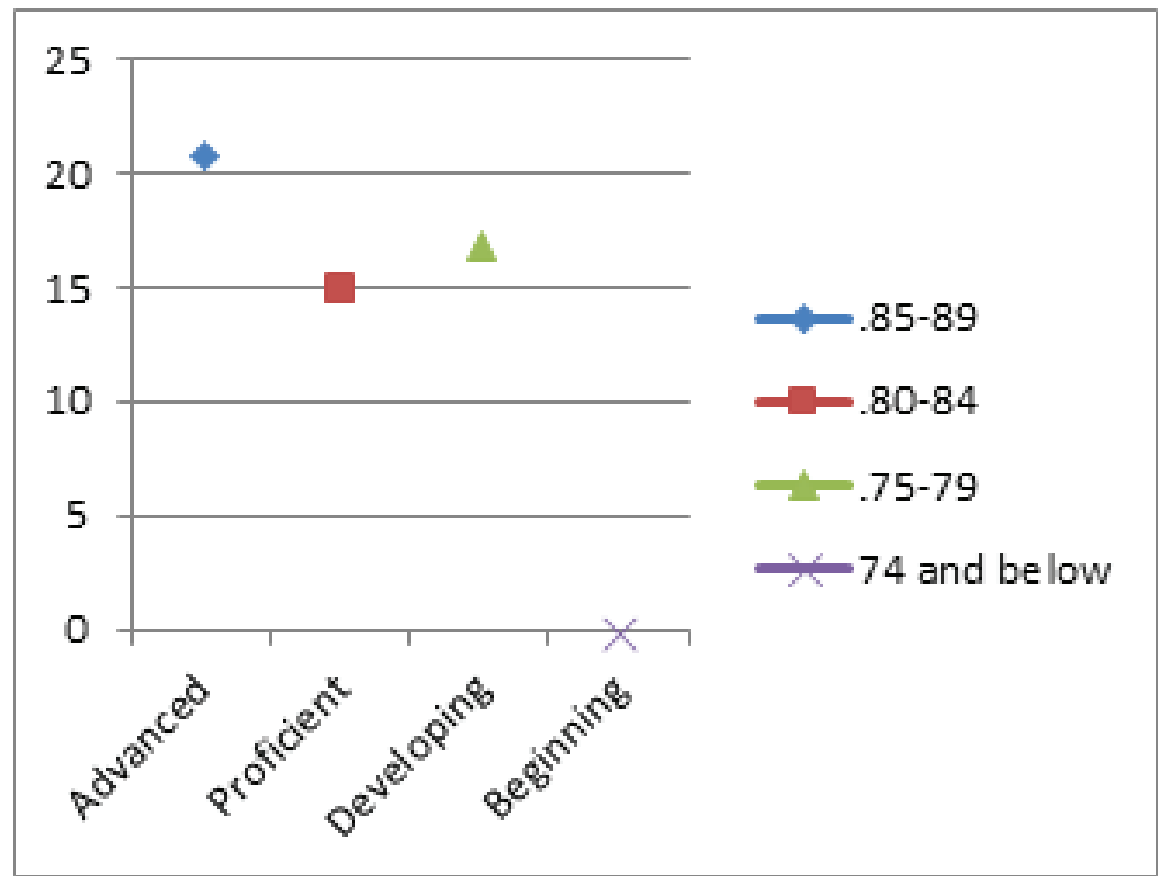

Figure 3: Academic Performance in Mathematics. 
Figure 3 shows the level of proficiency of the pupil respondents in their performance in Mathematics. Twenty-two (22) or 29.33 percent of the pupil respondents are proficient in their performance in Mathematics. Twenty-one (21) or 28 percent are advanced in their level of proficiency. It shows that more than half of the pupil-respondents performed well in Mathematics.

It is also manifested in the Figure that seventeen (17) or 22.67 percent of the pupil respondents are developing and fifteen (15) or 20 percent are approaching proficiency level.

TABLE 1: Figure of Intrapersonal Skills of the Pupil Respondents.

\begin{tabular}{|c|c|c|}
\hline & Intrapersonal Skills & Ranking \\
\hline 1 & It is easy to tell people how I feel. & 2 \\
\hline 2 & I can talk easily about my feelings. & 3 \\
\hline 3 & It is hard to talk about my deep feelings. & 5 \\
\hline 4 & I can easily describe my feelings. & 1 \\
\hline 6 & It is easy for me to tell people what I feel. & 6 \\
\hline & I have trouble in telling others about my \\
feelings. & \\
\hline
\end{tabular}

Table 1 shows the pupil-respondents' emotional quotient in terms of intrapersonal skills. It can be manifested that the pupil respondents can easily describe their feelings to others which ranks first having a weighted mean of 3.19 and with a verbal interpretation of often. It also shows that it is easy for them to tell people how they feel and ranks second with a weighted mean of 2.93 and a verbal interpretation of often.

It also shows that some pupil respondents can talk easily about their feelings, it is easy for them to tell people what they feel, while others find it hard for them to talk about their deep feelings to others and they have trouble telling others about their feelings with a weighted mean ranging from $2.60-2.89$ having

a verbal interpretation of often.

With an average weighted mean of 2.84 the pupil respondents intrapersonal skills are often expressed or manifested in their words and actions. It is an indicator that pupils in the elementary level often show and demonstrate their feelings honestly.

Intrapersonal skills, allow a person to use effective thought processes and mental habits to succeed in personal and professional relationships. Intrapersonal communication stems from both conscious and subconscious thoughts. Positive, productive intrapersonal thought processes contributed to effective decisions and actions. 
TABLE 2: Interpersonal Skills of the Pupil-Respondents.

\begin{tabular}{|c|c|c|}
\hline & Interpersonal Skills & Ranking \\
\hline & $\begin{array}{l}\text { I am good at understanding the way other } \\
\text { people feel. }\end{array}$ & 8 \\
\hline 2 & I care for what happened to other people. & 6 \\
\hline 3 & I usually know how other people are feeling. & 12 \\
\hline 4 & I am able to respect others. & 3 \\
\hline 5 & Having friends are important. & 1 \\
\hline 6 & I try not to hurt other people's feelings. & 5 \\
\hline 7 & I like doing things for others. & 7 \\
\hline 8 & I make friends easily. & 4 \\
\hline 9 & $\begin{array}{l}\text { I feel bad when other people have their } \\
\text { feelings hurt. }\end{array}$ & 9 \\
\hline 10 & I like my friends. & 2 \\
\hline 11 & $\begin{array}{c}\text { I can tell when one of my close friends is } \\
\text { unhappy. }\end{array}$ & 10 \\
\hline \multirow[t]{2}{*}{12} & $\begin{array}{c}\text { I know when people are upset, even when } \\
\text { they say nothing. }\end{array}$ & 11 \\
\hline & Average Weighted Mean & \\
\hline
\end{tabular}

Table 2 shows the pupil respondents' interpersonal skills. It can be gleaned that the pupil respondents found it important to have friends and they like to have friends manifested by a weighted mean of 3.64 and 3.61 , with verbal interpretation of very often. Second in rank is that the respondents like to have friends with a weighted mean of 3.61 and verbal interpretation of very often. But the respondent have a hard time of identifying whether the people around them are upset which ranks 11 with a weighted mean of 2.77 and verbal interpretation of often. They also often know how other people feel which ranks 12 in the interpersonal skills of the respondents with a weighted mean of 2.72 .

The respondents' interpersonal skills can be described as often with a weighted mean of 3.23. Making friends for them is very important and they like to win friends. They gave respect to others and did good things for others. They can easily sensed if their friends are unhappy or sad, upset or in bad mood. Even at their young age, they were aware of the different emotions and behavior of others.

\subsection{Stress scale}

Table 3 shows the pupil-respondents' emotional quotient in stress. It is manifested that the pupil respondents know how to keep calm and can stay calm even when 
TABLE 3: Pupil-Respondents' Emotional Quotient in Stress.

1
2
3
4
5
6
7
8
9
10
11
12

\begin{tabular}{l} 
Stress Scale \\
I can stay calm when I am upset. \\
It is hard to control anger. \\
I know how to keep calm. \\
I get too upset about things. \\
I fight with people. \\
I have a temper. \\
I get angry easily. \\
It takes a lot for me to get upset. \\
When I am mad at someone, I stay mad for a \\
long time. \\
\hline It is hard for me to wait for my turn. \\
I get upset easily. \\
When I get angry, I act without thinking. \\
Average Weighted Mean
\end{tabular}

Ranking
2
5
1
6
12
10
9
4
11
7
8
3

upset with a weighted mean of 3.39 and 3.08 with a verbal interpretation of often. When angry they can act without thinking with a weighted mean of 2.89 and verbal interpretation of often. The pupil-respondents also often takes longer time to get upset with a weighted mean of 2.83 . They can manage their stress often compared to other emotions.

The pupil-respondents find it hard to control their anger, to get too upset about thinks, to wait for their turn, easily get angry, they have a temper, when

mad at someone they stay mad or angry for a long time and they even fight with people with a weighted mean from 2.35 to 1.64 with a verbal interpretation of seldom. Their stress tolerance can be managed and controlled if not motivated by others. They often control their emotions of being angry and stay calm even when upset with an average weighted mean of 2.37. They seldom get angry even if they have temper. Their emotional quotient in stress is manageable at their early age.

Pupils got angry not only because of outside threats but also in response to their own feelings. This Figure shows that they can manage and control their emotions because they know how to keep calm and stay calm even if they were upset or angry.

\subsection{Adaptability scale}

It can be seen from Table 4 that the pupil-respondents' emotional quotients in adaptability is often manifested with an average weighted mean of 3.05. The first in rank is 
TABle 4: Pupil-Respondents Adaptability.

1
2
3
4
5
6
7
8
9
10

Adaptability Scale
I try to use different ways of answering hard
questions.
It is easy for me to understand new things.
I can understand hard questions.
I try to stick with a problem until I solve it.
I can come up with good answers to hard
questions.
I can come up with many ways of answering
a hard question when I want to.
I can easily use different ways of solving
problems.
When answering hard questions, I try to
think of many solutions.
I am good at solving problems.
Even if things get hard, I do not give up.
Average Weighted Mean

Ranking
7
5
10
2.5
9
2.5
6
1
8
4

when answering hard questions, they try to think of many solutions with a weighted mean of 3.40 and verbal interpretation of often.

Second in rank, the pupil respondents stick with a problem until they solve it and can come up with many ways of answering it, with a weighted mean of 3.17 and a verbal interpretation of often. Even if things get hard, they do not give up easily with a weighted mean of 3.15 and interpreted as often.

The last three in rank, the pupil respondents are good at solving problems, good in answering hard questions and can understand hard questions with a weighted mean ranging from 2.69 to 2.84 and verbally interpreted as often.

The pupil-respondents' adaptability is verbally described as often by answering hard questions, finding ways or solutions to solve it. Even when the problem is hard they do not easily give and try finding new ways and means to answer the problem.

\subsection{General mood scale}

The data gathered in Table 5 appear to suggest that the respondents are hopeful, joyful and contented in their appearance with the weighted mean of 3.61 and 3.57 with a verbal interpretation of very often. The respondents hope for the best, they are happy and they like the way they look. They are self-motivated meaning they look at the 
TABLE 5: Pupil-Respondents General Mood Scale.

1
2
3
4
5
6
7
8
9
10
11
12
13
14

General Mood Scale
I enjoy having fun.
I am happy.
I feel sure of myself.
I think that most thing I do will turn out okay.
I hope for the best.
I like to smile.
I know things will be okay.
I know how to have a good time.
I am not very happy.
I feel good about myself.
I am happy with the kind of person I am.
I enjoy the things I do.
I like my body.
I like the way I look.
Average Weighted Mean

Ranking
6
2.5
12
13
1
4
9
7
14
8
5
10
11
2.5

positive and brighter side of life. The pupil-respondents feel contented with oneself, others and life in general.

The last three in rank, pupil respondents feel sure of their self; do not think that everything they do will turn out okay which shows that when they do something they do not really expect the best result. The $12^{\text {th }}$ in rank has a weighted mean of 2.95 with a verbal interpretation of Often and $13^{\text {th }}$ in rank is they think that most thing they do will turn out okay. The Figure also shows that they are really joyful because the last in rank with a weighted mean of 1.75 and the verbal interpretation is often is I am not very happy. Their general mood scale has a weighted average of 3.24 and a verbal interpretation of often shows that the respondents look at the brighter side of life and feel contented with oneself and others and life in general.

The general mood scale includes optimism which is being positive and always looking for the good things in life and happiness which is a feeling of contentment with oneself, others and life in general.

\subsection{Positive impression scale}

The Positive Impression (PI) scale is designed to detect respondents who may be giving an exaggerated positive impression of themselves. The pupil respondents must always tell the truth which means they really want to be honest with a weighted mean of 3.57 
TABLE 6: Pupil-Respondents Positive Impression Scale.

1
2
3
4
5
6

Positive Impression Scale
I like everyone I meet.
I have good thoughts about everyone.
Nothing bothers me.
I must tell the truth.
I think I am the best in everything I do.
I do not have bad days.
Average Weighted Mean

\begin{tabular}{c} 
Ranking \\
3 \\
2 \\
6 \\
1 \\
5 \\
4 \\
\hline
\end{tabular}

and very often as the verbal interpretation and they always have good thoughts about everyone with a with weighted mean of 3.21 and often as the verbal interpretation.

Nothing bothers me item got the lowest weighted mean which is 2.40 which shows that the respondents really care about their self and others. The verbal interpretation which is seldom shows that they really care. The average weighted mean of 2.97 with a verbal interpretation of often shows that the respondents may have normal positive impression of themselves.

\subsection{Total emotional quotient}

TABlE 7: Pupil-Respondents Total Emotional Quotient of Summary of Scale Scores.

Gender /Age
Range
F-1
F-2
$M-1$
$M-2$

\begin{tabular}{|c|}
\hline Frequency \\
\hline 34 \\
18 \\
\hline 15 \\
\hline 8 \\
\hline
\end{tabular}

\begin{tabular}{c} 
Standard Scores \\
Weighted Mean \\
\hline 97.06 \\
107.83 \\
96.27 \\
96.63 \\
\hline
\end{tabular}

\begin{tabular}{|c|}
\hline Rank \\
\hline 4 \\
\hline 1 \\
\hline 3 \\
\hline 2 \\
\hline
\end{tabular}

\begin{tabular}{|c|}
\hline Verbal \\
Interpretation \\
\hline Average \\
\hline Average \\
\hline Average \\
\hline Average \\
\hline
\end{tabular}

Table 7 presents raw scores, standard scores for all obtained scores.

All the groups have a verbal interpretation of average which shows that they have adequate emotional and social capacity including coping for daily demands and pressures. The lowest standard scores weighted mean is the group of female ages 7 - 9 years which show that the younger females will still have some room for improvement in terms of emotional intelligence. The third in rank is the group of male ages 7- 9 with a weighted mean of 96.27. The last in rank and can be consider as the group with the highest emotional intelligence is the group of female ages $10-12$. This shows that older female students are more matured when it comes to emotional intelligence. 
1. Significant difference between the pupil respondents in terms of their emotional intelligence and profile variable.

TABLE 8: Respondents' Emotional Quotient in Terms of Their Gender.

Gender
Male
Female

\begin{tabular}{|c|}
$\begin{array}{c}\text { Weighted } \\
\text { Mean }\end{array}$ \\
\hline 2.89 \\
\hline 2.98 \\
\hline
\end{tabular}
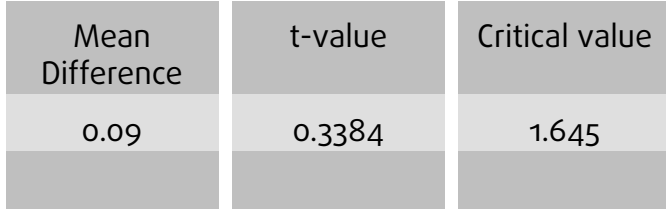

VI

Not significant

Table 8 shows that the respondents' emotional quotient had no significant difference in terms of their gender. Their emotional quotient is in terms of intrapersonal scale, interpersonal scale, stress management scale, adaptability scale, general mood scale and positive impression scale.

TABLE 9: Respondents' Emotional Quotient in terms of their Age.

\begin{tabular}{|c|c|c|c|c|c|}
\hline Age & $\begin{array}{c}\text { Average } \\
\text { Weighted } \\
\text { Mean }\end{array}$ & $\begin{array}{c}\text { Standard } \\
\text { Deviation }\end{array}$ & F-value & Critical Value & $\begin{array}{c}\text { Decision on } \mathrm{H}_{o} \\
\text { Interpretation }\end{array}$ \\
\hline $7-8$ & 2.84 & .3231 & 0.9519 & 3.59 & $\begin{array}{c}\text { Accept } \mathrm{H}_{o} \text { The } \\
\text { same }\end{array}$ \\
\hline $9-10$ & 3.05 & .3305 & & \\
\hline $11-12$ & 2.69 & .3163 & & \\
\hline
\end{tabular}

Table 9 shows that the respondents' emotional quotient are the same in terms of their age, their level of interpersonal, intrapersonal, stress, adaptability, positive impression and general mood are of the same level. There is no significant difference so the null hypothesis was accepted.

TABLE 10: Table of Difference Between Academic Performance and Emotional Quotient.

\begin{tabular}{l|c|c|c|c|}
\hline $\begin{array}{l}\text { Sources of } \\
\text { Variation }\end{array}$ & Df & Sum of Squares & Mean Square & $F_{\text {ratio }}$ \\
\hline Between & 3 & 0.69 & .23 & 0.00298 \\
\hline Within & 12 & 927.75 & 77.31 & \\
\hline Fo.05(3.12) $=3.49$ & & & & \\
\hline
\end{tabular}

Since the test statistics does not exceeds the critical value, the pupil respondents' academic performance and emotional quotient have no significant relationship. The emotional quotient does not affect the pupil respondents' academic performance. They have low positive relationship and are independent of one another. 


\section{Conclusion and Recommendation}

Based from the findings of the study academic performance in mathematics of the pupils were mostly in approaching proficiency, proficient and advanced level which shows that majority of the pupils perform well in mathematics.

The intrapersonal scale were above average, interpersonal scale were well developed, the stress scale were moderate, adaptability scale were above average, general mood scale, positive impression scale show that they were really honest and the total emotional intelligence of the pupils were on the average level or an adequate emotional and social capacity. The emotional quotient had no significant difference in terms of their gender and ages.

There is no correlation between the emotional intelligence and academic performance in mathematics of the elementary pupils of Batangas State University - ARASOF Laboratory School.

\section{Recommendations}

From the findings and conclusions of the study it is recommended another study composed of almost the same number of respondents according to ages and gender will be included.

The result of the study showed that majority of the pupils were above average in terms of their academic performance in math but the researcher recommend to improve the activities and strategies in teaching mathematics for the students whose academic performance is below average and give them different activities applicable on their level since the main concern of our educational system is to help all students especially students who finds math difficult. Emotional intelligence is seen as an important element in life based from the different studies. The emotional intelligence of the pupils should be maintained or improved by giving activities and advising sessions that increase awareness about emotional intelligence. Since there is no significant difference between the emotional intelligence and the age and gender of the pupils the researcher suggest to conduct additional activities about emotional intelligence and mathematics intended to all the students in the department. Different studies revealed significant correlation of emotional intelligence and academic performance for high school and college students, the researcher recommends to conduct further study 
about the reason why emotional intelligence has no significant relationship to academic performance in the elementary level. Implementation of the proposed development plan to improve emotional intelligence and academic performance in mathematics.

\section{Author's Note}

Dacillo, Lorna V. Iornadacillo@yahoo.com.ph 09273009218

\section{References}

[1] Bryant, Helen C.(2007) The Relationship Between Emotional Intelligence and Reading Comprehenshion in High School Students with Learning Disabilities.

[2] Thorndike, E.L."Intelligence and Its Uses". Harpers Magazine 1920

[3] Gardner, H..(2011) Frames of Mind. New York: Basic Book Inc.

[4] Mayer, J. D., Salovey, P., \& Caruso, D. R. (2004)Emotional Intelligence: Theory, Finding and Implication

[5] Festus, Asuka B.(2012) The Relationship Between Emotional Intelligence and Academic Achievement Of Senoir Secondary School Students in the Federal Capital Territory, Abuja National Mathematics Centre.

[6] Lee-Chua, Queena N.(2009) Psychologists talk about mathematics Philippine Daily Inquirer

[7] Imam, Ombra A, Abas-Mastura, Maripaz, Jamil Hajri (2012) Correlation between Reading Comprehension Skill and Student's Performance in Mathematics

[8] Erasmus, Petro (2013) Relationship Between Emotional Intelligence, Study Orientation in Maths And Maths Achievement of Middle Adolescent Boys and Girls 